\title{
1 Cover Page
}

2

3 Manuscript Title:

4 A macro-scale view of the influence of effective stress on carbon dioxide flow behaviour in coal:

$5 \quad$ An experimental study

6

7 Authors' names:

$8 \quad$ A.S. Ranathunga ${ }^{1}$, M.S.A. Perera ${ }^{1,2 *}$, P.G. Ranjith ${ }^{1}$ and G.P.D. De Silva ${ }^{1}$

9

$10{ }^{1}$ Deep Earth Energy Laboratory, Department of Civil Engineering, Monash University, Building 60,

11 Melbourne, Victoria, 3800, Australia.

$12{ }^{2}$ Department of Infrastructure Engineering, The University of Melbourne, Building 176,

13 Melbourne, Victoria, 3010, Australia.

14

15 Corresponding author:

16 Dr Mandadige Samintha Anne Perera

17 Department of Infrastructure Engineering,

18 The University of Melbourne,

19 Building 176, Melbourne, Victoria,

203010 , Australia.

21 Phone : Phone: +61-3-9035 8649

22 Fax: +61-3-9035 8649

23 E-mail: samintha.perera@unimelb.edu.au

24 


\section{Abstract}

26 Existing studies highlight the uncertainty in the process of $\mathrm{CO}_{2}$ sequestration in deep coal seams, mainly due to the associated $\mathrm{CO}_{2}$ adsorption-induced coal matrix rearrangements. This complexity is further increased by the highly heterogeneous nature of the coal mass which causes issues in

29 reproducing field conditions under laboratory conditions. The main objective of this study is 30 therefore to determine the permeability behaviour in coal for $\mathrm{CO}_{2}$ flow using macro-scale 31 reconstituted coal specimens $(203 \mathrm{~mm}$ in diameter and $1000 \mathrm{~mm}$ in length), particularly under 32 various effective stress conditions. A series of core flooding experiments was conducted on 33 Australian brown coal, using an advanced core flooding apparatus, for a range of $\mathrm{CO}_{2}$ injection 34 pressures and axial stresses. According to the findings, $\mathrm{CO}_{2}$ permeability decreases with increasing $35 \mathrm{CO}_{2}$ injection pressure, and the reduction is greater for super-critical $\mathrm{CO}_{2}$ at greater depths. The 36 critical zone of influence for $\mathrm{CO}_{2}$ injection into a selected coal seam is greater at lower injection 37 pressures and at shallow depths, and it reduces with increasing $\mathrm{CO}_{2}$ pressure and seam depth. $\mathrm{CO}_{2}$ 38 storage capacity in a selected coal seam is greater at lower depths and higher $\mathrm{CO}_{2}$ injection 39 pressures. However, the reduction of $\mathrm{CO}_{2}$ storage capacity with depth was not very significant, 40 which is important for field $\mathrm{CO}_{2}$ sequestration projects, which normally use deep seams to store $41 \mathrm{CO}_{2}$.

42 Keywords: $\mathrm{CO}_{2}$ storage; Coal permeability; Core flooding test; Effective stress; Low rank coal 


\section{Introduction}

Due to the capability of reducing the amount of anthropogenic carbon dioxide $\left(\mathrm{CO}_{2}\right)$ in the environment, $\mathrm{CO}_{2}$ sequestration in deep un-mineable coal seams has been identified as an effective method to address global warming (Jing et al. 2015; Verma and Sirvaiya 2016; White et al. 2005). Based on the fact that coal mass has higher affinity to $\mathrm{CO}_{2}$ than other gases like methane $\left(\mathrm{CH}_{4}\right)$ and nitrogen $\left(\mathrm{N}_{2}\right)$ due to its greater chemical and physical interaction, the sequestration process in return releases the coal bed methane $(\mathrm{CBM})$, which is an environmentally-friendly energy source with higher efficiency (White et al. 2005). However, according to the research literature (Day et al. 2008; Hol and Spiers 2012; Jing et al. 2015; Larsen et al. 1997; Pan and Connell 2007; Wang et al. 2013), the sequestration of $\mathrm{CO}_{2}$ disrupts the stability of the original coal structure with apparent changes in coal matrix swelling, which decreases the $\mathrm{CO}_{2}$ injectability into the coal seam and affects its longterm stability. It is therefore important to study the principles of coal mass swelling and to have a better understanding of the factors affecting this process.

A number of studies have been conducted on coal seam permeability upon $\mathrm{CO}_{2}$ sequestration and the effects of various factors on this have been highlighted, including injecting $\mathrm{CO}_{2}$ properties (Jasinge 2010; Day et al. 2008; Pan and Connell 2007; Perera et al. 2011; Siriwardane et al. 2009; Vishal and Singh 2015) and coal mass properties (Merkel et al. 2015; Wang et al. 2013). According to the research, potential coal seams for $\mathrm{CO}_{2}$ sequestration with higher temperatures and pressures have limited $\mathrm{CO}_{2}$ flow ability, because $\mathrm{CO}_{2}$ is in its super-critical state (beyond $7.38 \mathrm{MPa}$ pressure and $31.8^{\circ} \mathrm{C}$ temperature $\mathrm{CO}_{2}$ exists as super-critical fluid) and has higher sorption capacity in such seams.

On the other hand, it is well known that coal is a highly heterogeneous material and it is therefore quite difficult to validate the results obtained from natural coal samples for in-situ coal seams (De Silva 2013). Jasinge (2010) and Liu et al. (2016) found that reconstituted coal (RC) samples with reproducible properties can be used to successfully represent natural coal specimens, 
to overcome such difficulties. The following section focuses on some previous studies conducted on

69 RC and natural samples.

\section{0 \\ 1.1 Comparison of fluid flow behaviour in reconstituted and natural coal}

71 To date, many studies have been conducted to identify the flow behaviour in natural coal seams

72 using reconstituted coal samples and satisfactory results have been obtained. Fig. 1 illustrates a

73 study that compares $\mathrm{N}_{2}$ and $\mathrm{CO}_{2}$ permeability and related swelling in natural and reconstituted

74 Australian low rank coal (Jasinge, 2010).

(a)

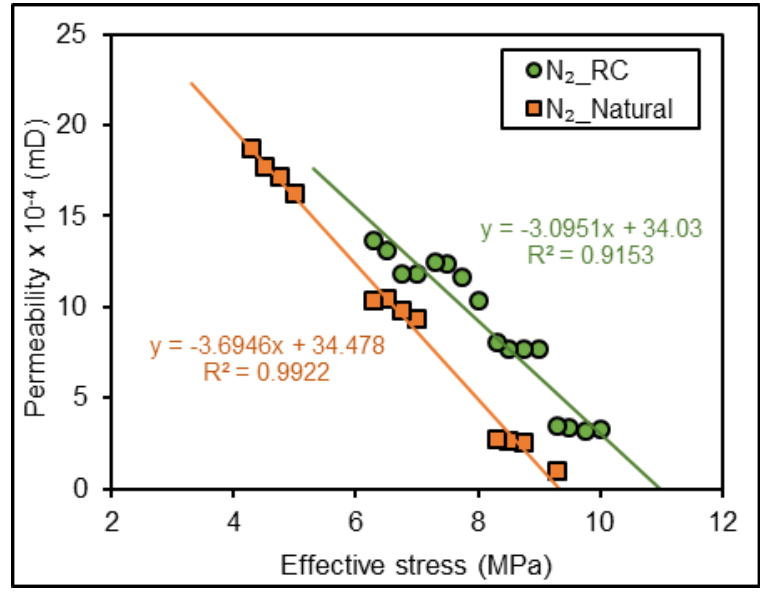

(c)

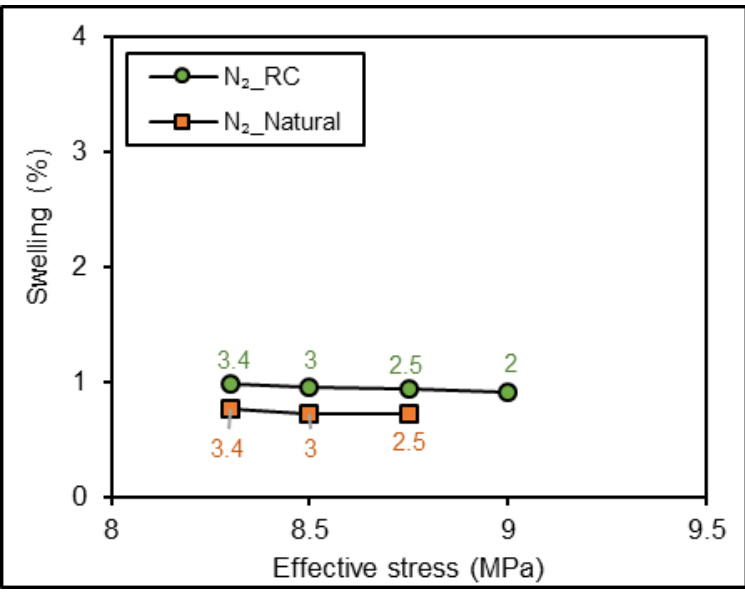

(b)

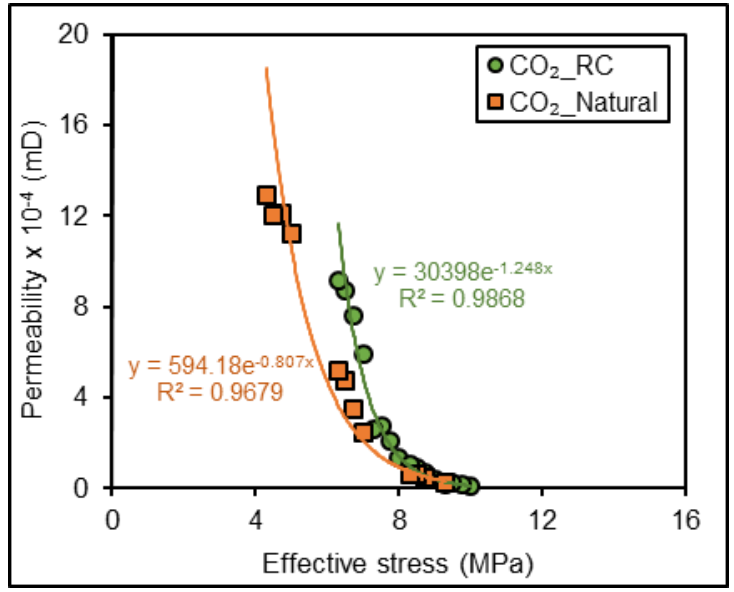

(d)

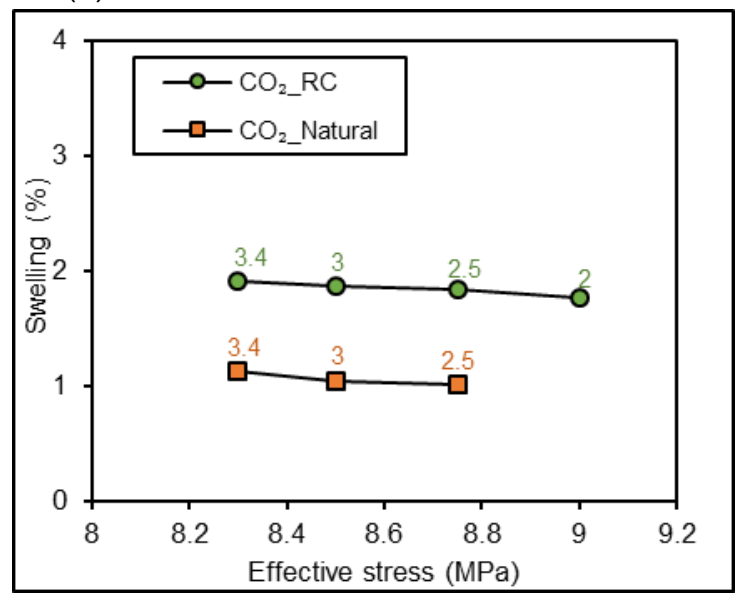

Fig. 1 (a) $\mathrm{N}_{2}$ and (b) $\mathrm{CO}_{2}$ permeability variation with effective stress and the variation of coal mass

swelling with (c) $\mathrm{N}_{2}$ and (d) $\mathrm{CO}_{2}$ flow for reconstituted coal (RC) and natural coal specimens

(Jasinge 2010) (The data labels in (c) and (d) denote the respective injection pressures) 
According to Fig. 1(a), $\mathrm{N}_{2}$ flow linearly reduces with increasing effective stress in both

80 natural and $\mathrm{RC}$ samples and $\mathrm{CO}_{2}$ flow (see Fig. 1(b)) follows a negative exponential variation, exhibiting an unfavourable effect of $\mathrm{CO}_{2}$ exposure to coal permeability. Further, the $\mathrm{RC}$ specimens show a higher permeability compared to the natural specimens for both $\mathrm{N}_{2}$ and $\mathrm{CO}_{2}$ flow (see Figs. 1(a) and (b)). Similar results were obtained by Liu et al. (2016) who injected $\mathrm{CH}_{4}(\sim 0.69 \mathrm{MPa})$ to coking coal (from Hexi coal mine, China) at different confining pressures (from around 2-7 MPa) which exhibited higher permeability for RC specimens than natural coal samples. This indicates the difference of fracture system characteristic such as fracture porosity and connectivity of the reconstituted coal sample and the natural coal sample. Further attention to coal mass swelling with $\mathrm{N}_{2}$ and $\mathrm{CO}_{2}$ permeation reveals that $\mathrm{N}_{2}$ injection does not show any significant variation in swelling with effective stress (see Fig. 1(c)) for both natural and RC samples. Conversely, $\mathrm{CO}_{2}$ flow causes the coal mass swelling to undergo an increasing trend with the increase of injection pressure (see Fig. 1(d)) for both natural and RC specimens. However, RC specimens display a comparatively higher coal matrix swelling compared to natural specimens during $\mathrm{CO}_{2}$ flow. This is probably caused by the higher amount of $\mathrm{CO}_{2}$ molecules enter to the coal mass (due to the higher permeability in RC samples compared to natural samples) which will interact with coal mass and create greater swelling. This may also contribute for the observed permeability variations (see Fig. 1(b)) having lower permeability reductions for natural samples than $\mathrm{RC}$ samples during $\mathrm{CO}_{2}$ permeation. However, the correlation between swelling and permeability of coal generally shows a similarity in both natural and RC specimens, allowing the use of RC specimens for experimental purposes (Jasinge 2010, Liu et al. 2016).

\subsection{Studies on $\mathrm{CO}_{2}$ flow behaviour using macro-scale coal specimens}

As recorded in the literature (Day et al. 2008; Jasinge 2010; Pan et al. 2010; Perera et al. 2011; Siriwardane et al. 2009; Sun et al. 2016; Vishal and Singh 2015), most coal $\mathrm{CO}_{2}$ injection studies have been conducted using meso-scale samples (up to around $100 \mathrm{~mm}$ in length). This has caused difficulties in confirming the applicability of adsorption theories at a higher scale to the estimation 

of $\mathrm{CO}_{2}$ storage capacity (De Silva 2013). Hence, De Silva (2013) conducted some advanced core-

106 flooding tests using $1 \mathrm{~m}$ long and $203 \mathrm{~mm}$ diameter (macro-scale) RC low rank coal samples to 107 effectively estimate the $\mathrm{CO}_{2}$ flow behaviour in coal to overcome the scale effect. De Silva (2013) 108 basically focused on the sub-critical $\mathrm{CO}_{2}$ flow in large coal samples and Ranathunga et al. (2015) 109 extended this study to super-critical $\mathrm{CO}_{2}$ to represent actual $\mathrm{CO}_{2}$ flow behaviour in deep coal seams, 110 considering the $\mathrm{CO}_{2}$ flow behaviour along the sample. The following sections summarise some 111 major findings of the macro-scale core flooding experiments conducted on $\mathrm{CO}_{2}$ injection.

113 De Silva (2013) conducted a series of tests of sub-critical $\mathrm{CO}_{2}$ injection (from $0.4 \mathrm{MPa}$ to $7.4 \mathrm{MPa}$ ) 114 under 1, 2, 4, 6 and $8 \mathrm{MPa}$ axial stresses and observed a reduction in $\mathrm{CO}_{2}$ permeability with 115 increasing $\mathrm{CO}_{2}$ injection pressure and axial stress (Fig. 2). $\mathrm{CO}_{2}$ adsorption-induced coal matrix 116 swelling is the main causative fact for this permeability reduction and this was proved by the related 117 swelling data (Fig. 2). According to Fig. 2, the coal volumetric strain is increased with increasing 118 injection pressure. Further, according to the figure, the increase of axial stress causes a reduction in 119 permeability for $\mathrm{CO}_{2}$ movement, probably due to the greater effective stresses applying on the coal mass.

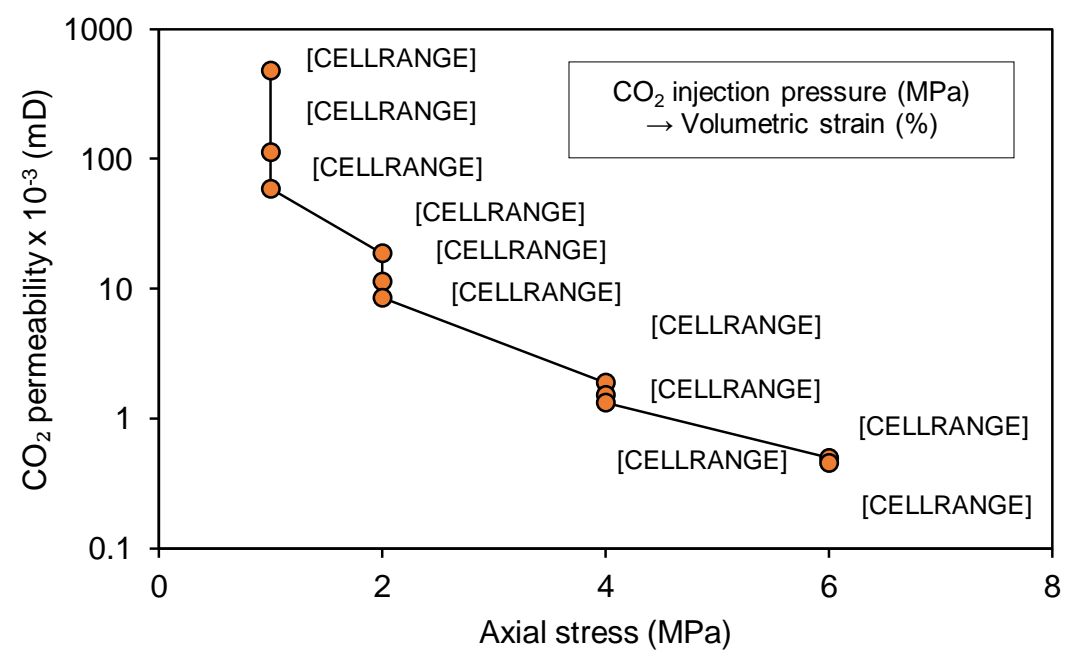


Fig 2. $\mathrm{CO}_{2}$ permeability variation with the axial stress and volumetric strain for different $\mathrm{CO}_{2}$ injection pressures (The first value of the label denotes the $\mathrm{CO}_{2}$ injection pressure (MPa) and the second value denotes the respective volumetric strain (\%)) (De Silva 2013)

126 As potential coal seams for $\mathrm{CO}_{2}$ sequestration undergo super-critical $\mathrm{CO}_{2}$ injection, Ranathunga et al. (2015) conducted a series of tests using super-critical $\mathrm{CO}_{2}$ to understand the variations of $\mathrm{CO}_{2}$ phase in large-scale coal specimens. They injected 6 to $10 \mathrm{MPa} \mathrm{CO}_{2}$ into low rank $\mathrm{RC}$ specimens under constant $38{ }^{\circ} \mathrm{C}$ temperature $\left(>31.8{ }^{\circ} \mathrm{C}\right.$, the critical temperature of $\left.\mathrm{CO}_{2}\right)$ and under $11 \mathrm{MPa}$ axial stress. They injected $\mathrm{N}_{2}$ before (first $\mathrm{N}_{2}$ injection) and after the $\mathrm{CO}_{2}$ injection (second $\mathrm{N}_{2}$ injection) to quantify the $\mathrm{CO}_{2}$ flow-induced coal mass changes and the $\mathrm{N}_{2}$ and $\mathrm{CO}_{2}$ permeability variations obtained are illustrated in Fig. 3.

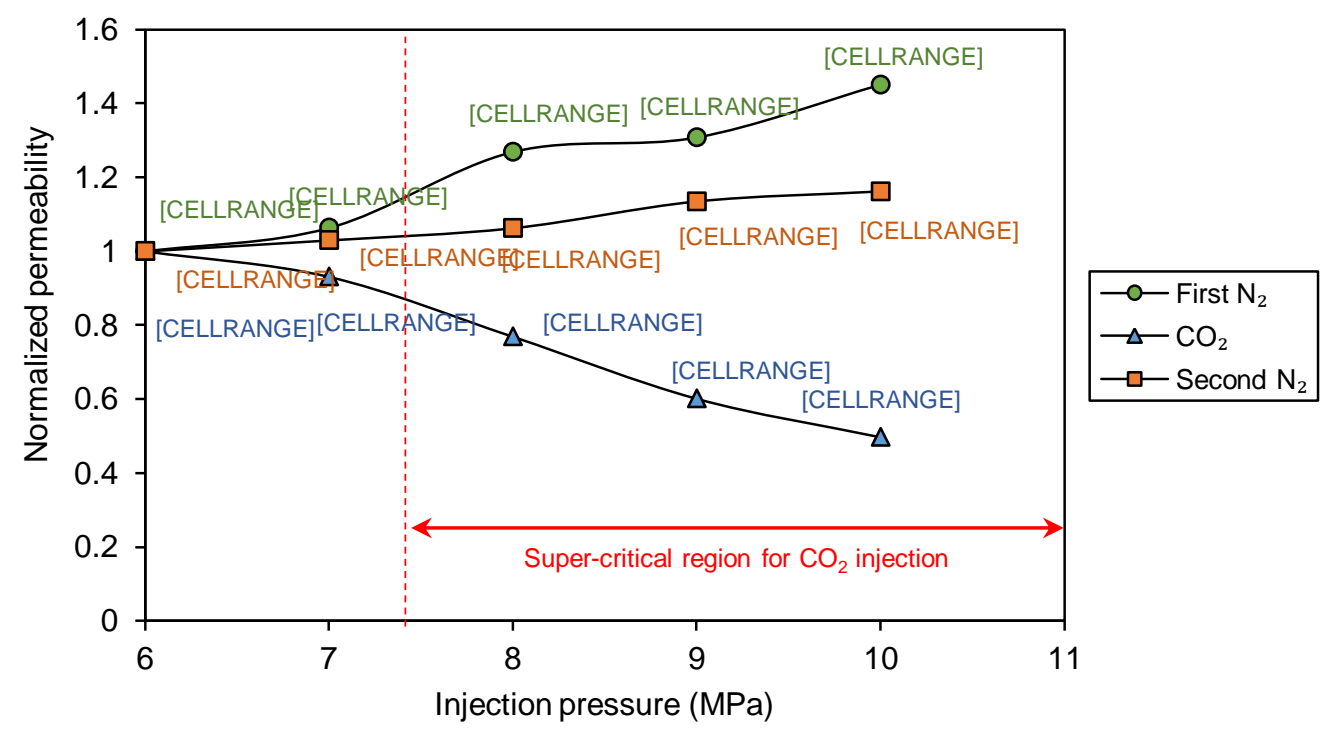

134 Fig 3. Permeability variation with different injection pressures for first $\mathrm{N}_{2}$ injection, $\mathrm{CO}_{2}$ injection and second $\mathrm{N}_{2}$ injection (Ranathunga et al. 2015) (The data labels indicate the coal specimen's volumetric strain (\%) under each injection condition. The permeability values have been normalized by dividing each value by the permeability obtained for $6 \mathrm{MPa}$ in each injection condition) 
140 However, it can be noted that the reduction is comparatively higher in the super-critical region 141 compared to sub-critical $\mathrm{CO}_{2}$. For example, there is around a 7\% decrease in permeability from 6 to $1427 \mathrm{MPa}$ sub-critical $\mathrm{CO}_{2}$ injection and around $21 \%$ permeability decrease from 8 to $9 \mathrm{MPa}$ super143 critical $\mathrm{CO}_{2}$ injection. This reduction is three times higher than in sub-critical $\mathrm{CO}_{2}$ flow. The main 144 reason for this observation is the higher adsorption capacity of super-critical $\mathrm{CO}_{2}$, as a result of its 145 greater chemically active nature, liquid-like density and viscosity that cause greater coal mass 146 swelling compared to sub-critical $\mathrm{CO}_{2}$ (Day et al. 2008). This is further evident from the volumetric 147 swelling data for both regions (see Fig. 3). Furthermore, the comparative reduction of the second $\mathrm{N}_{2}$ 148 flow compared to the first $\mathrm{N}_{2}$ flow clearly illustrates the coal mass changes which occur upon 149 exposure to $\mathrm{CO}_{2}$. For example, at $6 \mathrm{MPa}$, the first $\mathrm{N}_{2}$ to the second $\mathrm{N}_{2}$ injection shows around $17 \%$ 150 permeability reduction, and that for $8 \mathrm{MPa}$ is around $31 \%$. As $\mathrm{N}_{2}$ is a comparatively less adsorptive 151 gas compared to $\mathrm{CO}_{2}$ (Perera et al. 2011), this observed flow variation clearly occurs due to coal 152 mass swelling during $\mathrm{CO}_{2}$ flux. In addition, De Silva (2013) observed a decrease in $\mathrm{CO}_{2}$ permeability in coal with increasing effective stress (axial stress) for sub-critical $\mathrm{CO}_{2}$. Hence, it is important to investigate how supercritical $\mathrm{CO}_{2}$ flow changes with increasing effective stress. Ranathunga et al. (2016) conducted a series of meso-scale experiments to investigate this super-critical $\mathrm{CO}_{2}$ effect for similar low rank natural coal samples and observed the similar behaviour of $\mathrm{CO}_{2}$ flow and permeability reduction with increasing effective stress. Table 1, lists some of the results obtained by Ranathunga et al. (2016) for 6 to $7 \mathrm{MPa}$ (sub-critical $\mathrm{CO}_{2}$ ), 7 to $8 \mathrm{MPa}$ (the $\mathrm{CO}_{2}$ phase changing region), and 8 to 9 $\mathrm{MPa}$ (super-critical $\mathrm{CO}_{2}$ ) flow increments under 11,14 and $17 \mathrm{MPa}$ axial stresses.

According to Table 1, reduction of permeability with increasing effective stress is evident 162 and greater permeability reduction in deep coal seams is shown during $\mathrm{CO}_{2}$ sequestration. 163 Furthermore, this reduction is gradually increased when the $\mathrm{CO}_{2}$ phase is changed, being 164 comparatively greater in super-critical $\mathrm{CO}_{2}$ compared to sub-critical $\mathrm{CO}_{2}$. The opportunity for more 165 adsorptive super-critical $\mathrm{CO}_{2}$ molecules to interact with the coal matrix, creating increased matrix 
166

167

168

169

170

171

183 below.

rearrangements is the main reason for this observation (Perera et al. 2011). However, this may create complications for $\mathrm{CO}_{2}$-ECBM in deeper coal seams for $\mathrm{CO}_{2}$ injectability and productivity. Hence, further research is needed on this to gain better understanding of this phenomenon for application in the field.

Table 1. Variation of $\mathrm{CO}_{2}$ permeability with effective stress (Ranathunga et al. 2016)

\begin{tabular}{cccc}
\cline { 2 - 4 } Confining pressure (MPa) & $\begin{array}{c}\text { Permeability variation (\%) } \\
\text { tritical } \mathrm{CO}_{2} \text { flow } \\
\text { increment }\end{array}$ & $\begin{array}{c}7 \text { to } 8 \mathrm{MPa} \mathrm{CO}_{2} \text { phase } \\
\text { changing region }\end{array}$ & $\begin{array}{c}8 \text { to } 9 \mathrm{MPa} \text { super- }_{\text {critical } \mathrm{CO}_{2} \text { flow }} \\
\text { increment }\end{array}$ \\
\hline 11 (around 400m depth) & $-1.8^{*}$ & $-9.7^{*}$ & $-19.2^{*}$ \\
14 (around 500m depth) & $-7.6^{*}$ & $-12.4^{*}$ & $-25.1^{*}$ \\
17 (around 600m depth) & $-10.6^{*}$ & $-23.2^{*}$ & $-30.3^{*}$ \\
\hline${ }^{*}$ A negative sign indicates the permeability reduction & & &
\end{tabular}

A negative sign indicates the permeability reduction

The main objective of this study is therefore to develop knowledge of coal mass behaviour with $\mathrm{CO}_{2}$ exposure using macro-scale reconstituted low rank coal samples, particularly to identify the influence of axial stress on large-scale samples. The present study can therefore be considered as an extension of the work of De Silva (2013) and Ranathunga et al. (2015), which pays more attention to super-critical $\mathrm{CO}_{2}$ flow behaviour in coal located at various depth using macro-scale coal samples. An effort was also made to quantify the corresponding $\mathrm{CO}_{2}$ storage capacity variation with various effective factors $\left(\mathrm{CO}_{2}\right.$ phase, pressure and seam depth).

\section{Experimental methodology}

The advanced core-flooding apparatus available in the Deep Earth Energy Research Laboratory (DEERL) at Monash University (Fig. 4) was used to conduct this study. A detailed description of the apparatus can be found in De Silva (2013) and the experimental procedure is briefly described below.

\subsection{Sample preparation}

185 In this experiment RC samples were prepared using powdered low rank brown coal. The coal powder was obtained from coal blocks taken from the Hazelwood open-cut coal mine at Morwell in 
187 Gippsland, Victoria. The samples had a natural moisture content of around 55\%. The RC specimen

188 construction procedure is shown in Fig. 5, and the detailed methodology adopted to construct the

189 RC samples can be found in De Silva (2013) and Ranathunga et al. (2015).

(a)

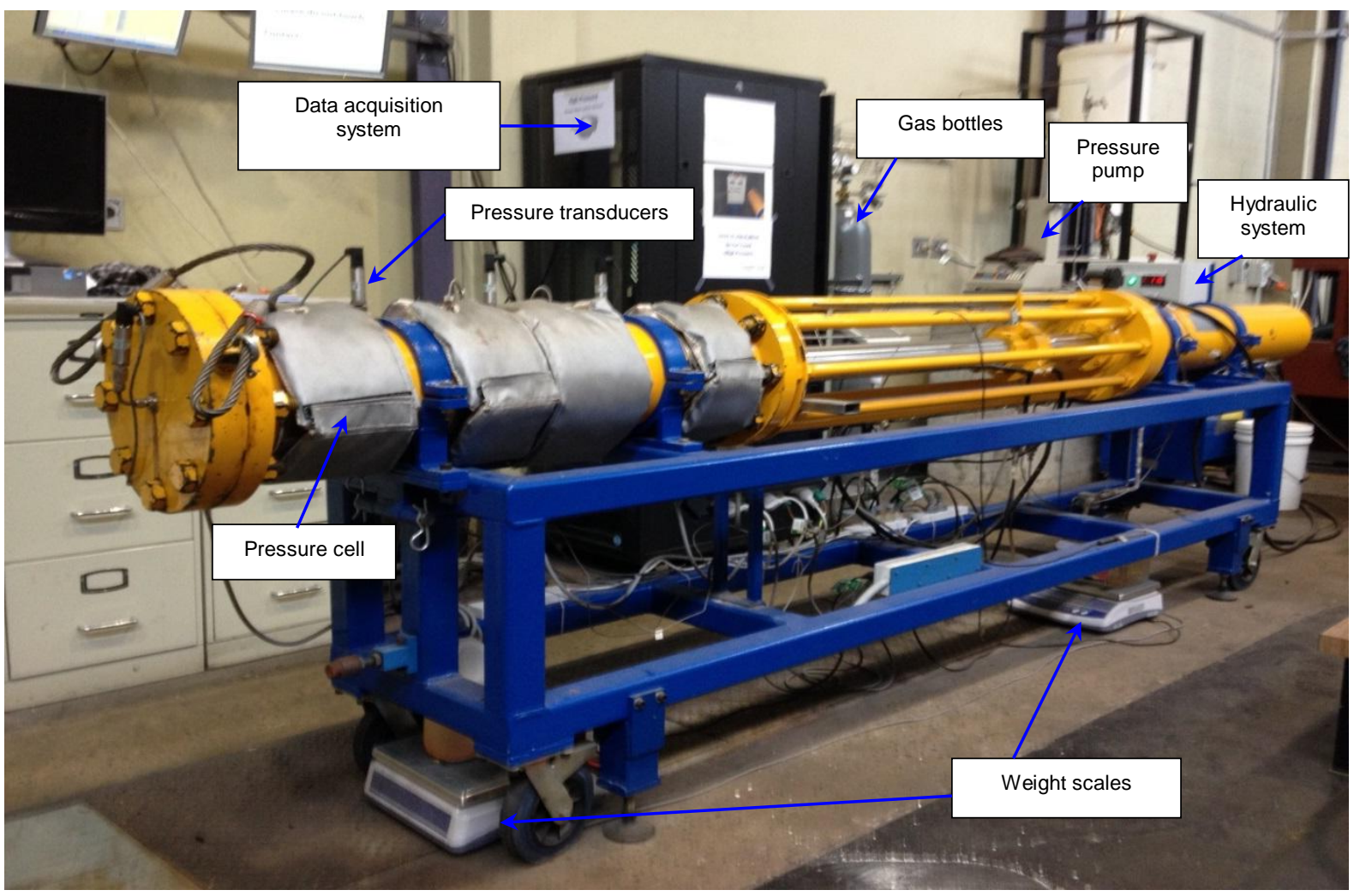

(b)

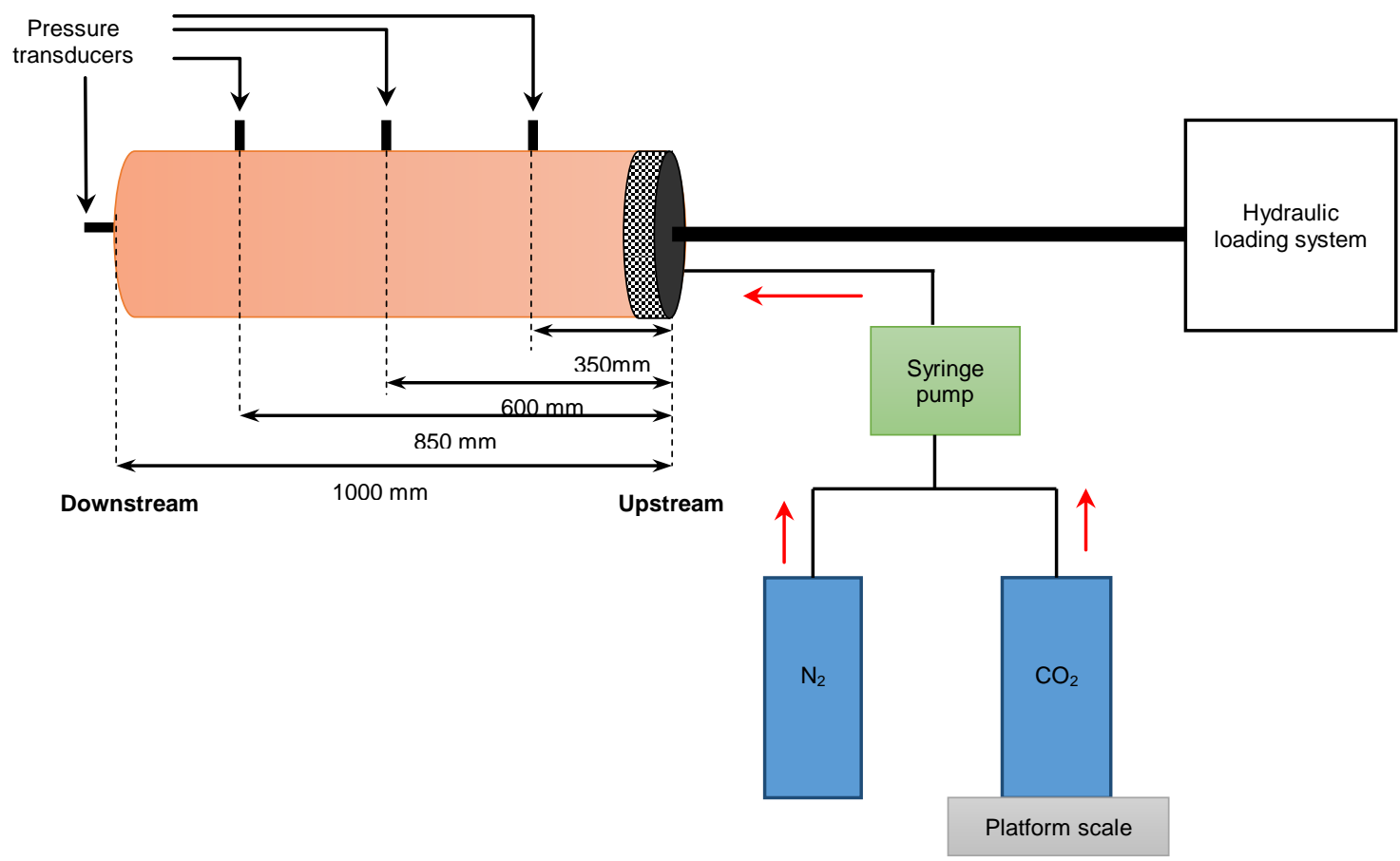


Fig 4. (a) Advanced core flooding apparatus (Ranathunga et al. 2015) and (b) the schematic

193

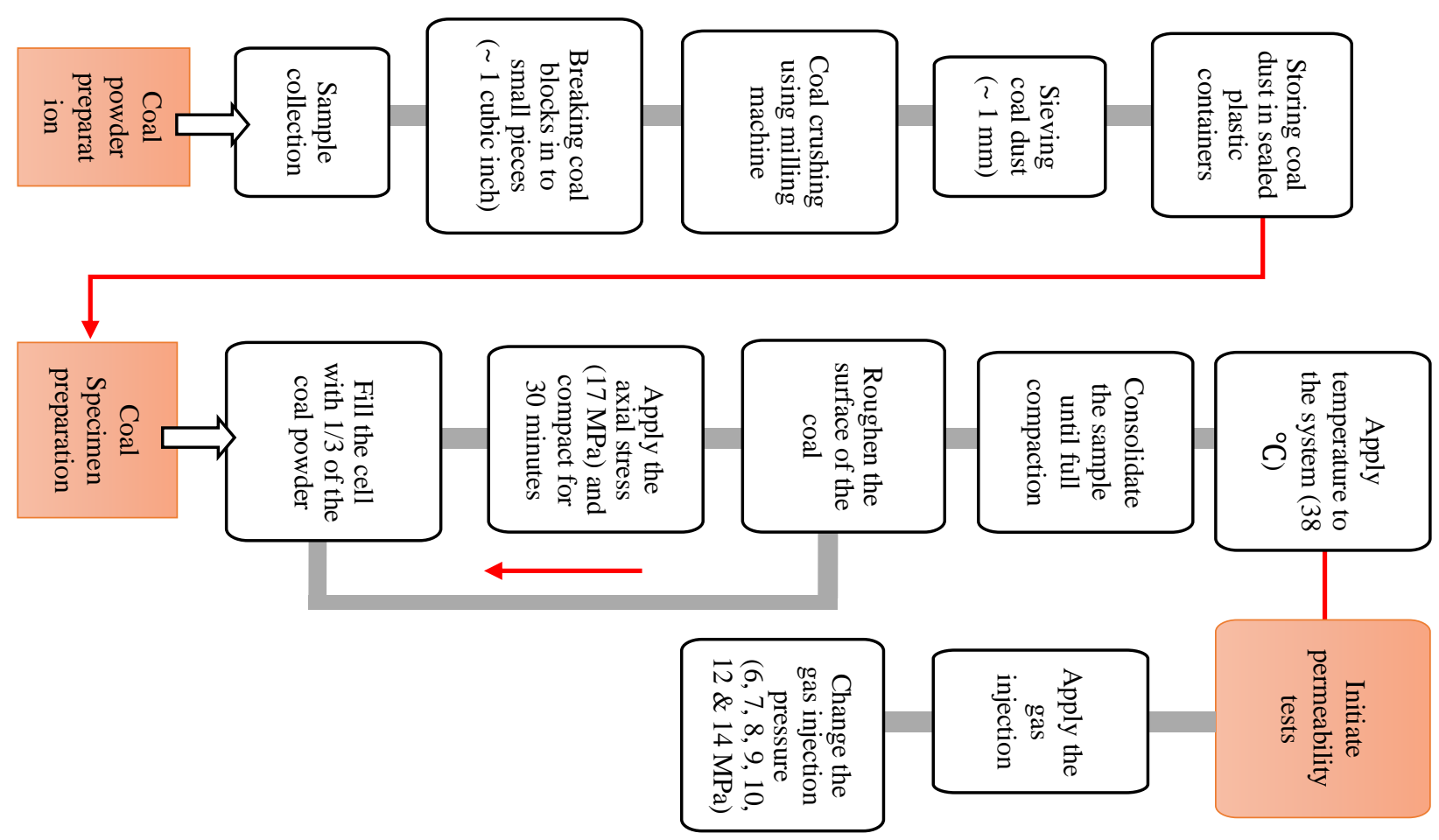

194

195

Fig 5. Experimental program for core flooding tests

\subsection{Permeability tests}

Permeability tests were conducted for $\mathrm{CO}_{2}$ injections at seven different injecting pressures $(6,7,8$, 9, 10, 12 and $14 \mathrm{MPa})$ under $17 \mathrm{MPa}$ axial stress, maintaining the system temperature at $38{ }^{\circ} \mathrm{C}$.

Since the system temperature was maintained at $38{ }^{\circ} \mathrm{C}, 6$ and $7 \mathrm{MPa} \mathrm{CO}_{2}$ injections were under subcritical conditions and the rest of the $\mathrm{CO}_{2}$ injections were under super-critical conditions (beyond 7.38 MPa pressure and $31.8^{\circ} \mathrm{C}$ temperature $\mathrm{CO}_{2}$ exists as a super-critical fluid). The undrained condition was maintained to determine the sample permeability, and the pressure-transient approach was used calculate the permeability (Pan et al. 2010; Perera et al. 2011). $\mathrm{CO}_{2}$ injection was performed, maintaining the injection pressure at a steady state at each injection pressure $(6,7,8,9$, 10, 12 and $14 \mathrm{MPa}$ ). The corresponding pressure developments at intermediate points along the sample and downstream were monitored and recorded using an advanced data acquisition system. 
208 the upstream and downstream vessels through the specimen calculated using Eqs. [1] and [2] (Pan 209 et al. 2010; Wang et al. 2015):

$210 \frac{\left(P_{u}-P_{d}\right)}{\Delta P_{0}}=e^{-\alpha t}$

$211 \alpha=\frac{k A}{\mu \beta L} V_{s}\left(\frac{1}{V_{u}}+\frac{1}{V_{d}}\right)$

212 where, $P_{u}$ is upstream vessel pressure, $P_{d}$ is downstream vessel pressure, $\Delta P_{0}$ is the step change of 213 pressure in vessels at time $=0, t$ is time, $k$ is permeability of the specimen, $A$ is cross-section area of 214 the sample $\left(0.0324 \mathrm{~m}^{2}\right), L$ is the length of the sample $(937 \mathrm{~mm}$ for this study after full 215 consolidation), $\mu$ is the viscosity of the injecting fluid, $\beta$ is the adiabatic compressibility of the 216 injecting fluid, $V_{s}$ is the sample volume, and $V_{u}$ and $V_{d}$ are the volume of upstream and downstream 217 pressure vessels, respectively. The viscosity and the adiabatic compressibility were calculated using 218 the REFPROP database (McLinden et al. 1998) for respective $\mathrm{CO}_{2}$ pressures and a constant 219 temperature $\left(38{ }^{\circ} \mathrm{C}\right)$. The pressure decay curves and corresponding permeability values of the 220 sample for $17 \mathrm{MPa}$ axial stress are shown in Fig. 6. 
(a)

(b)

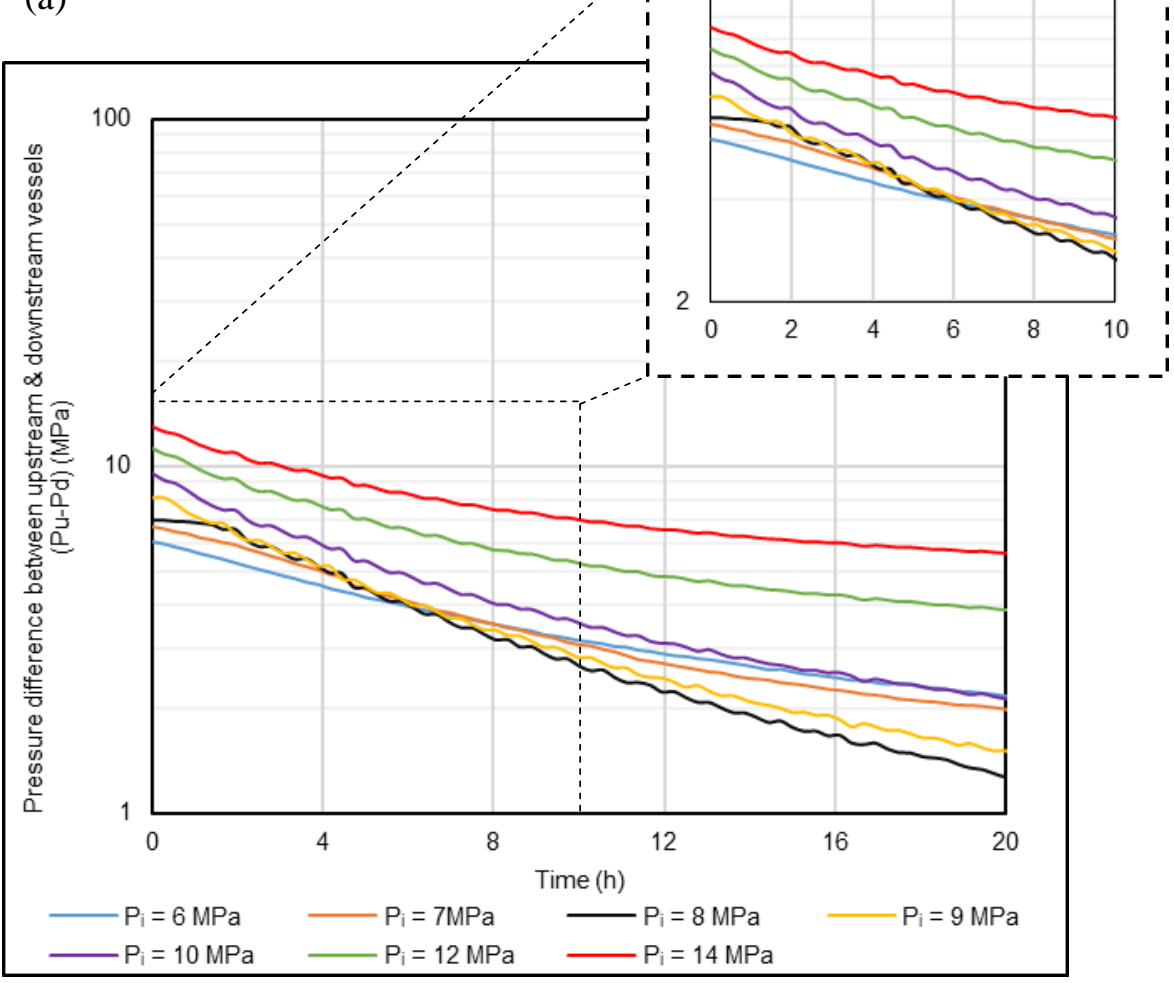

Fig 6. (a) Pressure decay curves (for 20 hours) and (b) $\mathrm{CO}_{2}$ permeability variation with $\mathrm{CO}_{2}$ injection pressures for $17 \mathrm{MPa}$ axial stress

\subsection{Coal matrix swelling measurements}

245 During each test, the sample length variation was recorded using a linear variable differential 246 transformer (LVDT) at 1s intervals to quantify the $\mathrm{CO}_{2}$ adsorption-induced coal matrix swelling in 247 the RC specimen. The volumetric swelling was then calculated using the measured length change of 
248 the sample using Eq. [3], because movement in the radial direction was restrained in the tests by the 249 steel casing. When the sample was subjected to swelling, the sample length was accordingly 250 increased and for a shrinkage, the sample length was consequently decreased.

251 Volumetric strain of the coal sample $=\frac{L_{t}-L_{0}}{L_{0}} \times 100 \%$

252 where, $L_{t}$ is the sample length at time $\mathrm{t}$ and $L_{o}$ is the sample length at time $\mathrm{t}=0$.

\section{$253 \quad 3 \quad$ Results and discussion}

254 A series of permeability tests was conducted for seven different $\mathrm{CO}_{2}$ injection pressures under 17 255 MPa axial stress using a macro-scale RC low rank coal sample, and the results obtained are 256 discussed in the following sections.

257 3.1 Carbon dioxide flow along the coal sample

258 3.1.1 Effect of injected carbon dioxide properties on coal mass permeability

259 According to Fig. 6(b), $\mathrm{CO}_{2}$ permeability reduces with increasing $\mathrm{CO}_{2}$ injection pressure at $17 \mathrm{MPa}$ 260 axial stress, and the reduction is relatively higher for super-critical $\mathrm{CO}_{2}$. For example, increasing the 261 injection pressure from 6 to $7 \mathrm{MPa}$ sub-critical $\mathrm{CO}_{2}$ flow caused around $11 \%$ permeability reduction 262 and increasing the injection pressure from 8 to $9 \mathrm{MPa}$ super-critical $\mathrm{CO}_{2}$ flow caused a much larger 263 permeability reduction of around 38\%. As explained previously, $\mathrm{CO}_{2}$ adsorption-induced coal 264 matrix swelling is the main causative factor for this observed permeability reduction with increasing 265 injection pressure. Similar results were reported by Ranathunga et al. (2015) for $11 \mathrm{MPa}$ axial 266 stress following similar macro-scale tests using the same type of RC coal samples, and a 267 comparison of $\mathrm{CO}_{2}$ permeability variations at 11 and $17 \mathrm{MPa}$ axial stresses with respective to 268 volumetric strain is presented in Fig. 7. 


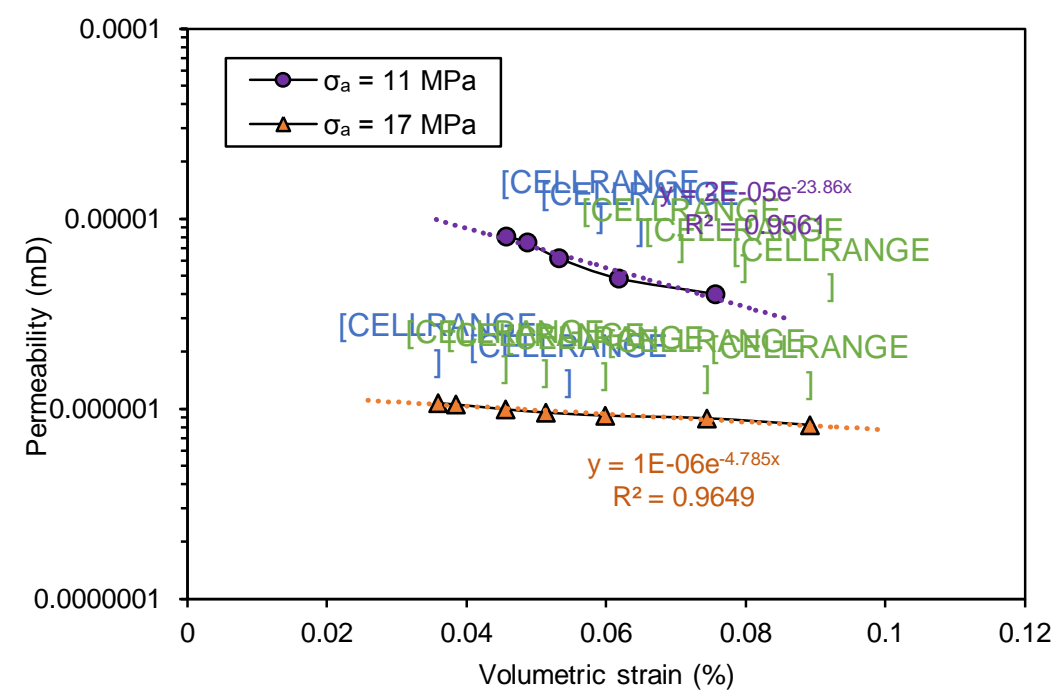

Fig 7. $\mathrm{CO}_{2}$ permeability vs. coal mass volumetric strain variation under $11 \mathrm{MPa}$ (Ranathunga et al.

2712015 ) and $17 \mathrm{MPa}$ axial stresses (Blue data labels denote sub-critical and green data labels denote super-critical $\mathrm{CO}_{2}$ injections)

According to Fig. 7, $\mathrm{CO}_{2}$ permeability and the volumetric swelling of the specimen follows

274 a negative exponential variation at both axial stresses, confirming the reason for the observed 275 reduced $\mathrm{CO}_{2}$ flow-ability with injection pressure. According to Day et al. (2010), higher adsorption 276 capacity of $\mathrm{CO}_{2}$ at higher pressures results in greater matrix alterations, causing reduced 277 permeabilities. Fig. 8 shows the variation of $\mathrm{CO}_{2}$ properties of viscosity and compressibility with 278 increasing $\mathrm{CO}_{2}$ pressure at $38{ }^{\circ} \mathrm{C}$ (the temperature used for the current experiment). According to 279 Fig. 8, $\mathrm{CO}_{2}$ properties are significantly changed in the super-critical region, where significant 280 increments in viscosity and reductions in compressibility with increasing pressure can be seen. This 281 inordinate increment of viscosity (see Figs. 8(a) and (c)) provides higher fluidity for super-critical $282 \mathrm{CO}_{2}$, which increases the adsorption capacity of the coal mass, and the reduction of compressibility 283 of super-critical $\mathrm{CO}_{2}$ (see Fig. 8(b)) constrains the amount of $\mathrm{CO}_{2}$ molecules entering the coal 284 matrix. These are the reasons for greater coal mass swelling and the lower permeabilities obtained 285 with increasing $\mathrm{CO}_{2}$ injection pressures. 
(a) (b)

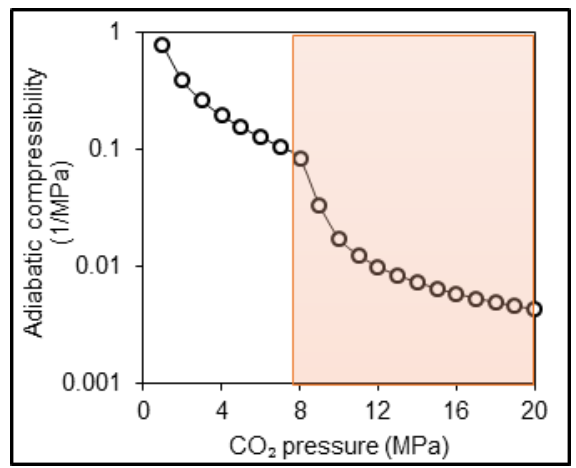

Fig 8. Variation of $\mathrm{CO}_{2}$ properties (a) viscosity and (b) compressibility with pressure (McLinden et al. 1998) (The shaded area is under super-critical conditions)

\subsubsection{Effect of coal seam depth on permeability}

According to Fig. 7, a reduction of permeability from 11 to $17 \mathrm{MPa}$ axial stress increment can be observed, similar to previous studies using small coal samples (Ranathunga et al. 2016; Vishal and Singh 2015). The disruptions to the flow with increased effective stresses cause these permeability decreases. However, the $\mathrm{CO}_{2}$ flow reduction is comparatively less for super-critical $\mathrm{CO}_{2}$ injection than for sub-critical $\mathrm{CO}_{2}$. For example, a reduction of around $86 \%$ for $6 \mathrm{MPa}$ sub-critical $\mathrm{CO}_{2}$ injection and around $80 \%$ for $8 \mathrm{MPa}$ super-critical $\mathrm{CO}_{2}$ injection can be seen when the axial stress is increased from 11 to $17 \mathrm{MPa}$. Similar results were obtained by Ranathunga et al. (2016) for small coal samples of similar low rank coal and these researchers observed $82 \%$ and $77 \%$ decrease of permeability for $6 \mathrm{MPa}$ (sub-critical) and $9 \mathrm{MPa}$ (super-critical) $\mathrm{CO}_{2}$ injections for 11 to $17 \mathrm{MPa}$ confining pressure increase. This may be due to the already reduced flow with higher coal mass swelling and higher effective stress application in deeper coal seams that lead only to a lower reduction of super-critical $\mathrm{CO}_{2}$ flow. This suggests that that, regardless of sample size, the effect of seam depth on its permeability is significant.

As discussed in Section 3.1.1, an increase of $\mathrm{CO}_{2}$ injection pressure from 6 to $7 \mathrm{MPa}$ (subcritical flow) and 8 to $9 \mathrm{MPa}$ (super-critical flow) cause a permeability reduction of $11 \%$ and $38 \%$ respectively for $17 \mathrm{MPa}$ axial stress. For similar $\mathrm{CO}_{2}$ injection pressure increments during $11 \mathrm{MPa}$ axial stress, Ranathunga et al. (2015) observed around 5\% (6 to $7 \mathrm{MPa}$ ) and 23\% (8 to $9 \mathrm{MPa}$ ) 
permeability reductions for similar macro-scale RC samples made with the same brown coal. This

308 implies that the permeability reduction with increasing injection pressure observed at $17 \mathrm{MPa}$ axial 309 stress is higher than the reduction observed at $11 \mathrm{MPa}$ axial stress (Ranathunga et al. 2015). Similar 310 results have been obtained for a meso-scale study by Ranathunga et al. (2016) for similar rank coal 311 samples, which showed around $2 \%$ and $11 \%$ permeability reductions for 11 and $17 \mathrm{MPa}$ confining 312 pressures when $\mathrm{CO}_{2}$ injection pressure was increased from 6 to $7 \mathrm{MPa}$, and $19 \%$ and $30 \%$ 313 permeability reductions when $\mathrm{CO}_{2}$ injection pressure was increased from 8 to $9 \mathrm{MPa}$ at the same 314 confining pressures (see Table 1). The reason is the lower flow ability at higher applied effective 315 stresses, which offers a longer residential time for the $\mathrm{CO}_{2}$ molecules within the coal mass. This 316 may lead to higher matrix alterations causing lower permeability, especially for super-critical $\mathrm{CO}_{2}$ 317 flow (Vishal and Singh 2015).

The other important fact is that the coal matrix swelling is comparatively less at $17 \mathrm{MPa}$ 319 than for $11 \mathrm{MPa}$ axial stress (see Fig. 7). For example, around $0.045 \%$ and $0.036 \%$ volumetric strains can be seen for $6 \mathrm{MPa}$ (sub-critical) $\mathrm{CO}_{2}$ flow and $0.053 \%$ and $0.046 \%$ for $8 \mathrm{MPa}$ (supercritical) $\mathrm{CO}_{2}$ flow under $11 \mathrm{MPa}$ and $17 \mathrm{MPa}$ axial stresses, respectively (see Fig. 7). This may be due to the obstruction of sample length variation by the higher stresses applying at higher axial stresses (recall Section 2.3). In addition, this volumetric strain increment with injection pressures is higher for $11 \mathrm{MPa}$ axial stress compared to $17 \mathrm{MPa}$ axial stress. For instance, a 6 to $7 \mathrm{MPa}$ subcritical $\mathrm{CO}_{2}$ flow increment shows around $7.2 \%$ and $4 \%$ volumetric strain increases for 11 and 17 $\mathrm{MPa}$ axial stresses, while that for 8 to $9 \mathrm{MPa}$ super-critical flow is around $16.1 \%$ and $12.6 \%$, respectively (see Fig. 7). Similar results have been reported by Jasinge (2010) for RC low rank coal 328 of a similar type. Jasinge (2010) observed around $8.9 \%$ and 3.8\% swelling increments for 9 to 10 $329 \mathrm{MPa}$ confining pressure increments when $\mathrm{CO}_{2}$ pressure was increased from 2.5 to $3.4 \mathrm{MPa}$. As explained previously, the higher effective stresses acting on the coal mass at greater axial stresses 331 slow down the $\mathrm{CO}_{2}$ flow along the coal matrix, offering less opportunity for $\mathrm{CO}_{2}$ to interact with 332 the coal mass by increasing the matrix rearrangements. Hol et al. (2011) also confirmed this 
observation after finding a lower $\mathrm{CO}_{2}$ sorption capacity for bituminous coal due to the higher in situ stresses applied on coal mass which will result in lesser matrix swelling. This shows the lower coal matrix swelling effect expected for $\mathrm{CO}_{2}$ injection at greater seam depths. This is preferable for $\mathrm{CO}_{2}$ sequestration as most of the potential seams for $\mathrm{CO}_{2}$ sequestration process are at quite deep depths

337 (> $1 \mathrm{~km})$.

\subsubsection{How does carbon dioxide flow behaviour vary along the seam?}

339 As discussed in Sections 3.1.1 and 3.1.2, lower $\mathrm{CO}_{2}$ injection pressures at shallow depths produce 340 higher permeability through the coal mass, while higher $\mathrm{CO}_{2}$ pressures at deeper depths cause flow 341 reduction with enhanced coal matrix swelling and higher effective stresses applied on the coal mass. 342 The meso-scale study conducted by Perera et al. (2011) for black coal (high rank), showed a 343 considerable reduction in pressure along the coal mass during $\mathrm{CO}_{2}$ injection. For example, around 6 $344 \mathrm{MPa}$ downstream pressure was observed for $10 \mathrm{MPa} \mathrm{CO}_{2}$ injection under $15 \mathrm{MPa}$ confinement and 345 around $3 \mathrm{MPa}$ for $20 \mathrm{MPa}$ confinement for the same injection pressure. Similar lower pressure 346 gradients were observed by Ranathunga et al. (2015) for a low rank macro-scale coal sample, and 347 non-linear pressure variation along the specimen could be seen. Therefore, it was interesting to 348 study how this $\mathrm{CO}_{2}$ flow varies through the coal sample length (937 $\mathrm{mm}$ for the current study) 349 during each injection conditions under this greater axial stress condition. Fig. 9 illustrates how the $350 \mathrm{CO}_{2}$ pressure varied along the length of the sample during $6 \mathrm{MPa}$ (sub-critical) and $8 \mathrm{MPa}$ (super351 critical) $\mathrm{CO}_{2}$ injections at both 11 and $17 \mathrm{MPa}$ axial stresses at the end of injection period measured 352 using intermediate pressure transducers (see Fig. 4). The injection period was the duration of time 353 taken to reach to the steady state at downstream and the additional 10 days (approximately) allowed 354 for swelling-induced matrix changes.

As shown in Fig. 9, the respective injection pressures dropped gradually from upstream to downstream, regardless of injection pressure or depth (axial stress). The important thing is that this decrease is greater at higher injection pressures (super-critical) and higher depths compared to 
stress caused a decrease of $21.4 \%$ from upstream to downstream, while the same injection under 17

$360 \mathrm{MPa}$ axial stress caused a greater reduction of 32.9\%. In addition, $8 \mathrm{MPa}$ super-critical $\mathrm{CO}_{2}$ flow 361 under $11 \mathrm{MPa}$ axial stress produced a $29.8 \%$ drop in pressure, and $17 \mathrm{MPa}$ axial stress caused a 362 greater reduction of $43.6 \%$. These lower pressure gradients caused lower permabilities through the 363 sample (Fig. 7). Interestingly, the injected pressure remained constant up to around $500 \mathrm{~m}, 200 \mathrm{~m}$, $364400 \mathrm{~m}$ and $50 \mathrm{~m}$ during $6 \mathrm{MPa}$ and $8 \mathrm{MPa} \mathrm{CO}_{2}$ injection under $11 \mathrm{MPa}$ and $17 \mathrm{MPa}$ axial stress 365 respectively. Nevertheless, this length reduced with increasing injection pressure and axial stress. 366 Hence, it can be deduced that the critical zone of influence (area of $\mathrm{CO}_{2}$ injection pressure kept 367 constant) during $\mathrm{CO}_{2}$ injection into a coal seam is larger at lower injection pressures at shallow 368 depths, while it is reduced when higher $\mathrm{CO}_{2}$ pressures are injected into deeper coal seams. This is 369 important for the $\mathrm{CO}_{2}$ storage process in deep coal seams. Furthermore, only around $50 \%$ of the sample is under super-critical conditions under 11 $371 \mathrm{MPa}$ axial stress for $8 \mathrm{MPa} \mathrm{CO}_{2}$ injection, and this proportion become less (around $25 \%$ of the 372 sample) under $17 \mathrm{MPa}$ axial stress (see Figs. 9(c) and (d)). This observation clearly indicates the 373 lower volumetric strain increments at higher effective stresses (refer to Section 3.1.2). The reason is 374 that the coal matrix alterations due to more adsorptive super-critical $\mathrm{CO}_{2}$ occur over a smaller area 375 of the sample due to the lower permeabilities at higher effective stresses. Hence, the volumetric 376 strain increment is lesser at greater depths than shallow depths. 


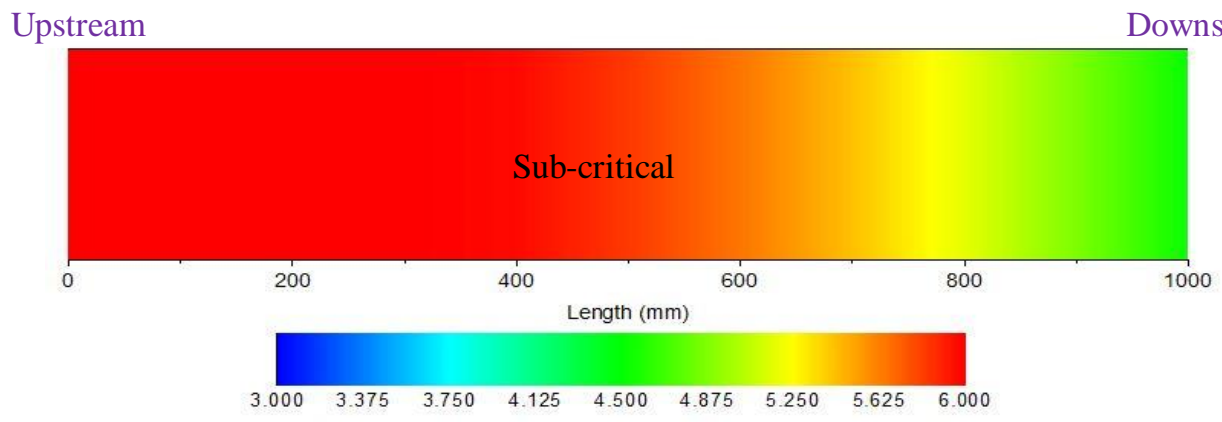

(a) $\mathrm{P}_{\mathrm{i}}=6 \mathrm{MPa} ; \sigma_{\mathrm{a}}=11 \mathrm{MPa}$
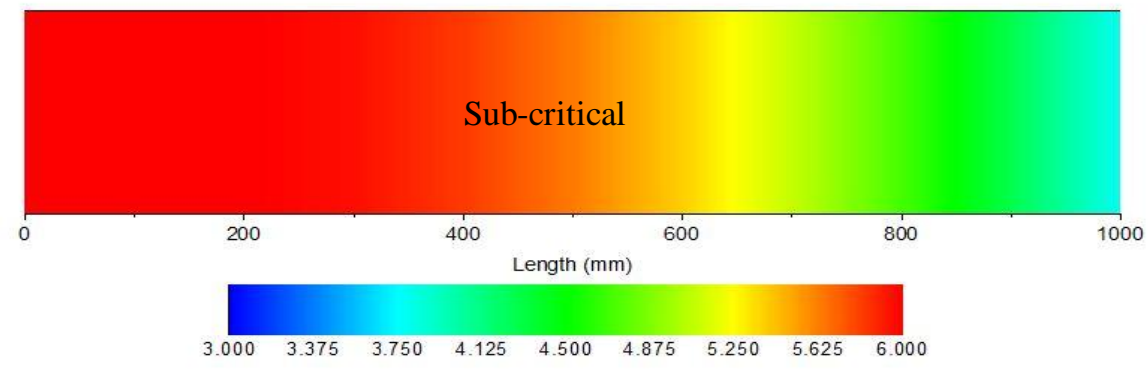

(b) $\mathrm{P}_{\mathrm{i}}=6 \mathrm{MPa} ; \sigma_{\mathrm{a}}=17 \mathrm{MPa}$
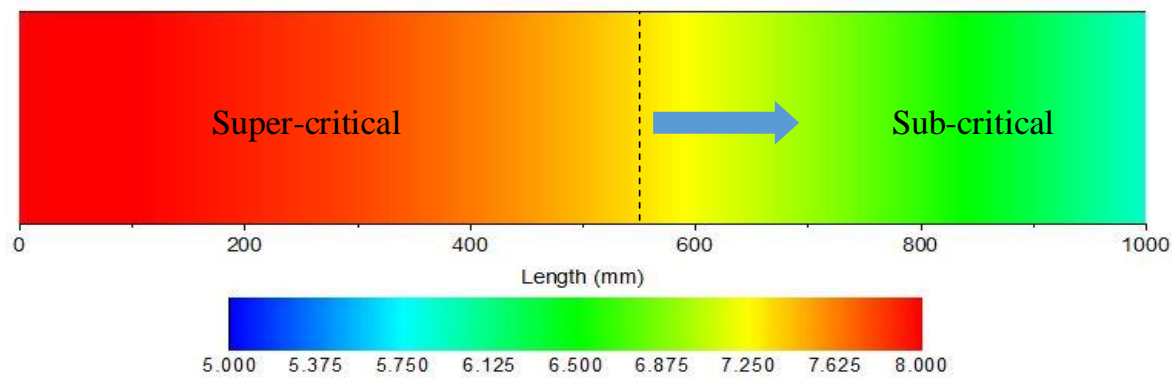

(c) $\mathrm{P}_{\mathrm{i}}=8 \mathrm{MPa} ; \sigma_{\mathrm{a}}=11 \mathrm{MPa}$
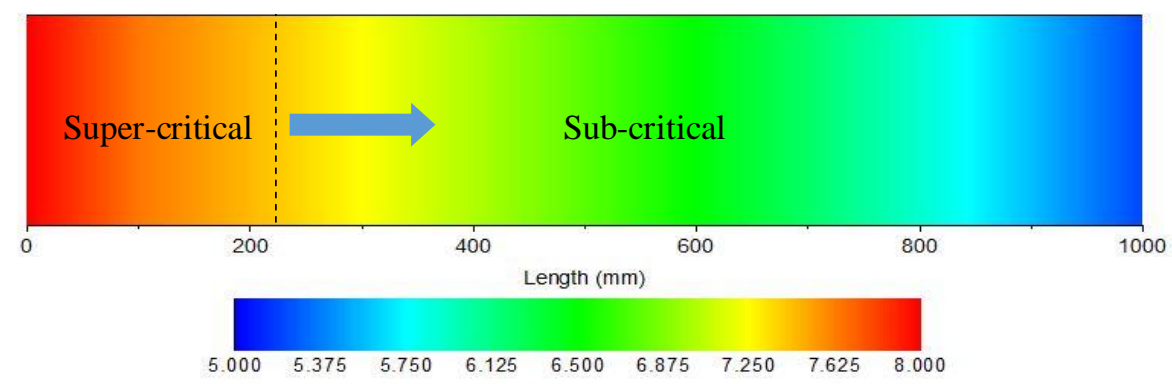

(d) $\mathrm{P}_{\mathrm{i}}=8 \mathrm{MPa} ; \sigma_{\mathrm{a}}=17 \mathrm{MPa}$

378 Fig 9. Pressure variation along the length of the sample after injection period under $11 \mathrm{MPa}$

379 (Ranathunga et al. 2015) and $17 \mathrm{MPa}$ axial stresses (Here, $\mathrm{P}_{\mathrm{i}}$ is injection pressure and $\sigma_{\mathrm{a}}$ is axial 380 stress. The colour scale of each figure depicts the $\mathrm{CO}_{2}$ pressure (in MPa) variation along the coal sample) 
383 As $\mathrm{CO}_{2}$ permeability along the coal sample varies with both axial stress and $\mathrm{CO}_{2}$ injection pressure, 384 a multi-variable regression equation was developed for permeability variations using the 385 experimental data from Ranathunga et al. (2015) and the present study. Refer to Eq. [4]:

$\mathrm{k}=\mathrm{e}^{\left(-0.2944 \sigma_{\mathrm{a}}-0.1105 \mathrm{P}_{\mathrm{i}}-7.9127\right)}$

$$
\mathrm{R}^{2}=0.936
$$

387 where, $\sigma_{a}$ is axial stress $(\mathrm{MPa}), P_{i}$ is $\mathrm{CO}_{2}$ injection pressure $(\mathrm{MPa})$ and $k$ is $\mathrm{CO}_{2}$ permeability $(\mathrm{mD})$.

388 The predicted permeability variations with the axial stresses and $\mathrm{CO}_{2}$ injection pressures are shown 389 in Fig. 10. Fig. 10 clearly indicates that $\mathrm{CO}_{2}$ permeability is higher at lower axial stresses and lower $390 \mathrm{CO}_{2}$ injection pressures. In addition, it is reduced gradually with the increment of both axial stress and $\mathrm{CO}_{2}$ injection pressure, confirming the experimental observations.

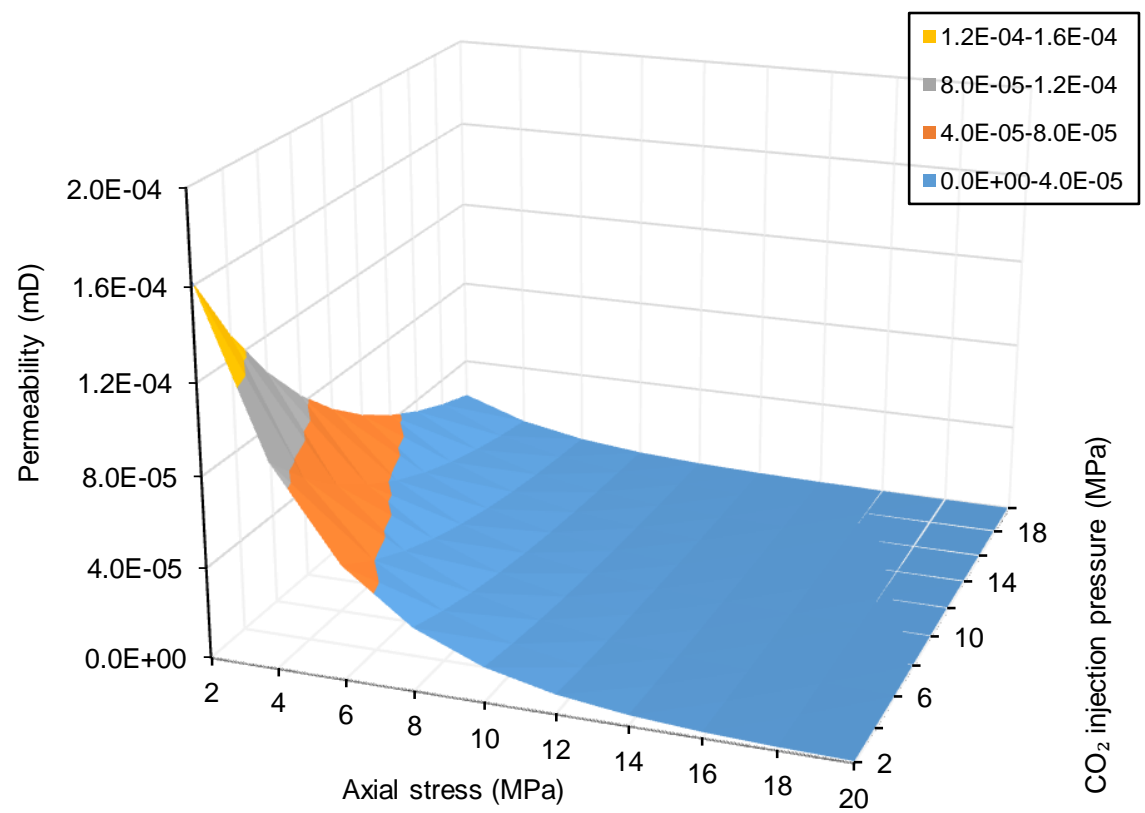

Fig 10. Predicted permeability variation with axial stress and $\mathrm{CO}_{2}$ injection pressure

\section{2 $\mathrm{CO}_{2}$ storage capacity variation}

One of the main purposes of $\mathrm{CO}_{2}$-ECBM process is to store anthropogenic $\mathrm{CO}_{2}$ in deep unmineable coal seams. It is therefore vital to investigate the amount of $\mathrm{CO}_{2}$ that can be stored in the coal mass under various conditions, including various seam depths (axial stress) and injecting fluid properties $\left(\mathrm{CO}_{2}\right.$ phase and pressure). The next stage of analysis was therefore to quantify the $\mathrm{CO}_{2}$ 
storage capacity in the coal mass under the various test conditions. This was accurately monitored 400 using a digital platform scale at the $\mathrm{CO}_{2}$ injection point. The amount of gas injected was monitored 401 over time after changing the injection pressure and maintaining it for more than 10 days, to allow 402 sufficient time for swelling. Fig. 11 shows the variation in amount of injected $\mathrm{CO}_{2}$ into the coal 403 mass (after around 10 hours) with effective stress under $11 \mathrm{MPa}$ and $17 \mathrm{MPa}$ axial stress conditions 404 at each injection pressure. The effective stress was calculated as the difference between the applied 405 axial stress and the mean gas pressure (the average of the pressures applied at upstream and 406 downstream).

407

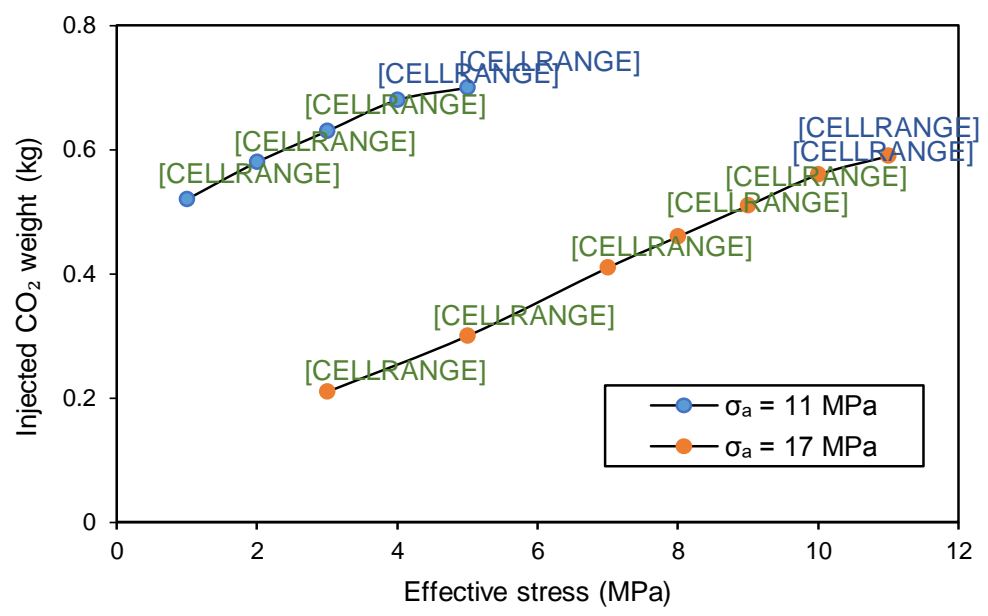

Fig 11. Variation of injected $\mathrm{CO}_{2}$ weight (after 10 days) and $\mathrm{CO}_{2}$ permeability with effective stress for 11 and $17 \mathrm{MPa}$ axial stresses (The blue data labels denote the sub-critical and the green data labels denote the super-critical $\mathrm{CO}_{2}$ injections).

According to Fig. 11, the amount of injected $\mathrm{CO}_{2}$ is increased with increasing effective stress for both 11 and $17 \mathrm{MPa}$ axial stresses. This increment is greater when the $\mathrm{CO}_{2}$ injection pressure is greater than $7 \mathrm{MPa}$ (super-critical flow) and lower for 6 to $7 \mathrm{MPa}$ (sub-critical flow) $\mathrm{CO}_{2}$ injections. For example, around $4.9 \%$ increment in injected $\mathrm{CO}_{2}$ weight was observed from 6 to $7 \mathrm{MPa}$ pressure increment, and that for 8 to $9 \mathrm{MPa}$ was $14.9 \%$ at $11 \mathrm{MPa}$ axial stress. Similarly, for $17 \mathrm{MPa}$ axial stress, the injected $\mathrm{CO}_{2}$ weight was around $1.9 \%$ for an increase from 6 to $7 \mathrm{MPa}$ pressure and $9.8 \%$ for 8 to $9 \mathrm{MPa}$ pressure increment. The main reason for this observation is the reduction of $\mathrm{CO}_{2}$ flow with increasing injection pressure (see Fig. 7) due to the coal matrix 
rearrangements which require less $\mathrm{CO}_{2}$ injection into the coal sample. Furthermore, the higher the axial stress, the greater the effective stress application, which causes greater reductions in $\mathrm{CO}_{2}$ injectivity (see Fig. 10).

However, this $\mathrm{CO}_{2}$ storage process is time-dependent, and longer time offers more opportunity for $\mathrm{CO}_{2}$ adsorption and storage. Fig.12 shows the injected $\mathrm{CO}_{2}$ weight variation with time at $6 \mathrm{MPa}$ (sub-critical) and $8 \mathrm{MPa}$ (super-critical) injection pressures under both 11 and 17 $\mathrm{MPa}$ axial stresses. According to Fig. 12, the cumulative weight of injected $\mathrm{CO}_{2}$ increases over time, and the rate of increase is lower at higher $\mathrm{CO}_{2}$ injection pressures and at greater axial stresses. For

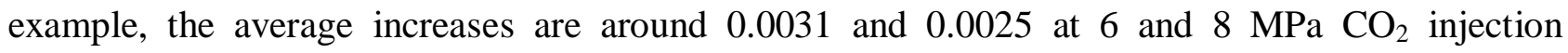
pressures under $11 \mathrm{MPa}$ axial stress, while they are around 0.0008 and 0.0005 for the same injection pressures $\left(6\right.$ and $8 \mathrm{MPa}$ ) under $17 \mathrm{MPa}$ axial stress. This observation clearly explains the $\mathrm{CO}_{2}$ storage behaviour observed in Fig. 11, which shows greater $\mathrm{CO}_{2}$ storage capacity at lower depths and lower $\mathrm{CO}_{2}$ injection pressures.

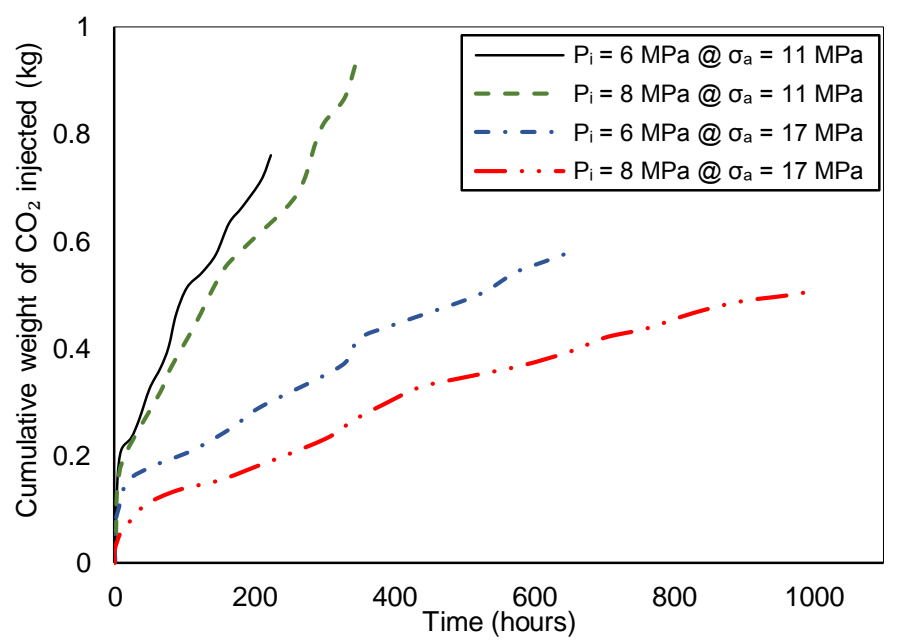

Fig 12. Cumulative weight of injected $\mathrm{CO}_{2}$ variation with time for $6 \mathrm{MPa}$ and $8 \mathrm{MPa}$ injection Interestingly, in relation to the weight of $\mathrm{CO}_{2}$ injected at the end of the injection period, a 436 contrasting behaviour compared to that shown in Fig. 11 was obtained. Fig. 13 illustrates a pressures at $11 \mathrm{MPa}$ and $17 \mathrm{MPa}$ axial stresses comparison of the weight of $\mathrm{CO}_{2}$ injected after 10 days of injection and at the end of the injection 
period under both 11 and $17 \mathrm{MPa}$ axial stresses. According to Fig. 13, it can be noted that, although

439 flow ability reduces at higher $\mathrm{CO}_{2}$ injection pressures, a comparatively larger amount of $\mathrm{CO}_{2}$ can be 440 stored if a long time is offered for $\mathrm{CO}_{2}$ sequestration at greater depths. The reason is, as stated in 441 Fig. 8, the inherent liquid-like properties of super-critical $\mathrm{CO}_{2}$ permit greater adsorption potential 442 with the coal matrix, which requires some time to complete.

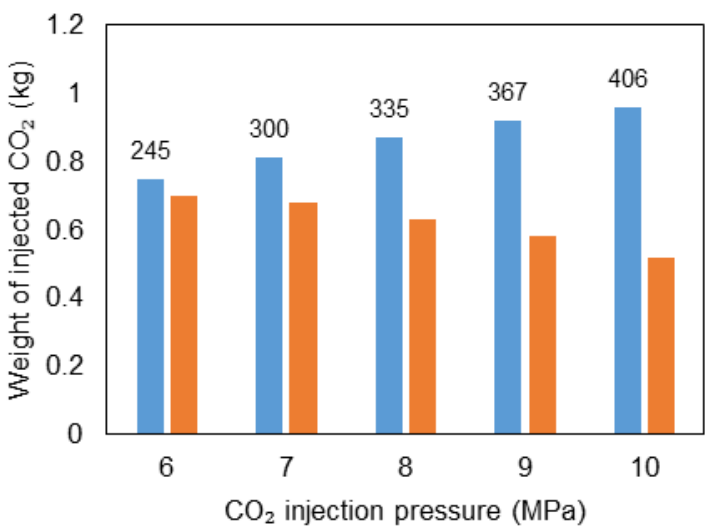

$\backsim$ After completing the injection period $\quad$ After 10 days of injection (a)

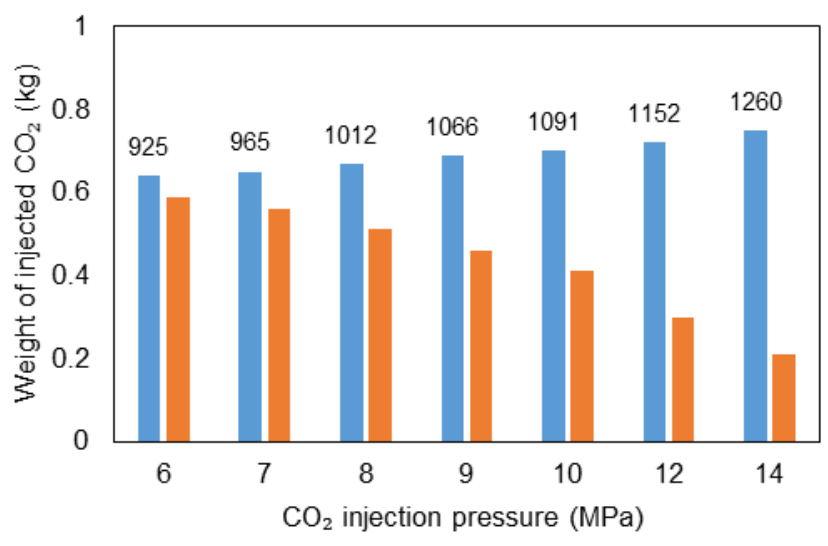

$\varpi$ After completing the injection period $\quad$ After 10 days of injection

(b)

Fig 13. Comparison of weight of $\mathrm{CO}_{2}$ injected after completing the injection period and after 10 days during (a) $11 \mathrm{MPa}$ axial stress and (b) $17 \mathrm{MPa}$ axial stress (The data labels denote the injection

However, in the case of $\mathrm{CO}_{2}$ storage capacity variation with axial stress, the injected $\mathrm{CO}_{2}$ 448 weight reduction with axial stress is not much lower compared to the permeability reduction 449 observed with axial stress (see Fig. 7). A comparison of the observed permeability reductions and 450 the $\mathrm{CO}_{2}$ storage capacity reductions under 11 to $17 \mathrm{MPa}$ axial stress increment is shown in Table 2.

451 Table 2. Comparison of permeability and $\mathrm{CO}_{2}$ injectivity reductions with $11 \mathrm{MPa}$ to $17 \mathrm{MPa}$ axial

\begin{tabular}{ccccc}
\cline { 2 - 5 } & $\begin{array}{c}\mathrm{CO}_{2} \text { injection } \\
\text { pressure }(\mathrm{MPa})\end{array}$ & $\begin{array}{c}\text { Permeability } \\
\text { reduction }(\%)\end{array}$ & $\begin{array}{c}\text { Injected } \mathrm{CO}_{2} \text { weight }_{4} \\
\text { reduction }(\%)\end{array}$ \\
\hline \multirow{2}{*}{ Sub-critical region } & 6 & 86.72 & 27.08 & 454 \\
& 7 & 85.96 & 25.01 & \\
\hline \multirow{3}{*}{ Super-critical region } & 8 & 83.98 & 22.99 & 455 \\
& 9 & 80.31 & 19.75 & \\
\hline
\end{tabular}

es 
According to Table 2, similar to permeability reduction, the injected $\mathrm{CO}_{2}$ or stored $\mathrm{CO}_{2}$ 459 weight is greatly reduced in the super-critical region, and the permeability reduction is around 460 60 70\% higher than the injected $\mathrm{CO}_{2}$ weight reductions (see Table 2). The higher residential time 461 for $\mathrm{CO}_{2}$ molecules with higher effective stresses may offer greater adsorption possibility for $\mathrm{CO}_{2}$ 462 molecules with the coal matrix (De Silva 2013) with time and the inceraesd amount of $\mathrm{CO}_{2}$ 463 molecules enter to the coal mass at higher $\mathrm{CO}_{2}$ pressures, warranting lower reductions than in flow 464 ability.

\section{Suggestions for $\mathrm{CO}_{2}$-ECBM field applications}

466 Potential coal seams for $\mathrm{CO}_{2}$-ECBM are located deep underground, where the injected $\mathrm{CO}_{2}$ is in its 467 super-critical state (beyond 7.38 MPa and $31.8^{\circ} \mathrm{C}$ ). The liquid-like viscosities (see Fig. 8) of super468 critical $\mathrm{CO}_{2}$ provide more potential for stable $\mathrm{CO}_{2}$ storage within the coal matrix. Nevertheless, the 469 observed decrease in $\mathrm{CO}_{2}$ flow ability along the coal matrix, especially during super-critical $\mathrm{CO}_{2}$ 470 injection, raises concerns concerning the productivity of the ECBM process. On the other hand, 471 according to the findings, regardless of the permeability reductions, $\mathrm{CO}_{2}$ storage capacity in coal 472 increases with increasing injection pressure upon offering sufficient time for sequestration. 473 Furthermore, a comparatively lower reduction of $\mathrm{CO}_{2}$ storage capacity was witnessed with 474 increasing axial stress from $11 \mathrm{MPa}$ (representing an approximately $400 \mathrm{~m}$ deep coal seam) to 17 $475 \mathrm{MPa}$ (representing an approximately $600 \mathrm{~m}$ deep coal seam). This information is very useful for $\mathrm{CO}_{2}$ sequestration field projects, because there is current interest in utilising extremely deep underground coal seams for $\mathrm{CO}_{2}$ sequestration. According to current findings, this depth effect does 478 not have such a great influence on $\mathrm{CO}_{2}$ storage potential.

However, attention should be paid to the flow reductions which occur with the coal matrix 480 swelling, because this might affect long-term $\mathrm{CO}_{2}$ sequestration processes by allowing more $\mathrm{CO}_{2}$ 
adsorption, which has been witnessed in several field-scale projects (White et al. 2005). Therefore,

the implementation of flow-enhancement techniques (e.g. hydro fracturing, alternative injection of

$483 \mathrm{~N}_{2}$ ) (White et al. 2005) will provide more opportunities to store greater amounts of $\mathrm{CO}_{2}$ in deeper 484 coal seams.

485 Hence, resolving complications when using super-critical $\mathrm{CO}_{2}$ for $\mathrm{CO}_{2}$-ECBM recovery in 486 terms of $\mathrm{CO}_{2}$ storage capacity and $\mathrm{CH}_{4}$ production enhancement using flow-enhancement 487 techniques is essential prior to field-scale projects.

\section{Conclusions}

489 Following a series of $\mathrm{CO}_{2}$ permeability tests using macro-scale low rank coal specimens, the 490 following conclusions can be drawn:

$491>\mathrm{CO}_{2}$ permeability in coal is greater at lower depths and lower $\mathrm{CO}_{2}$ injection pressures, while it 492 gradually reduces with increasing depth and injection pressure, and the associated effective stress variation and the coal matrix swelling caused by $\mathrm{CO}_{2}$ adsorption are the main causative 494 factors, respectively.

$495>$ Super-critical $\mathrm{CO}_{2}$ causes greater swelling in the coal mass compared to sub-critical $\mathrm{CO}_{2}$, and 496 the swelling increases with increasing injection pressure, regardless of depth. This swelling 497 increment is however reduced with increasing seam depth, probably due to the associated 498 greater effective stresses effect that obstructs $\mathrm{CO}_{2}$ flow along the coal matrix, offering less 499 opportunity for $\mathrm{CO}_{2}$ to interact with the coal mass.

$500>$ The permeability variation along the coal sample under the tested coal seam and injecting $\mathrm{CO}_{2}$ 501 conditions can be effectively represented using a simple multivariable regression model, and 502 such models play an important role in field projects to predict $\mathrm{CO}_{2}$ flow migration along the 503 seam.

$504>$ The observed $\mathrm{CO}_{2}$ permeability along the tested coal specimen indicated that the critical zone 505 of influence for $\mathrm{CO}_{2}$ injection into a selected coal seam is greater at lower injection pressures 506 and at shallow depths, and it this reduces with increasing $\mathrm{CO}_{2}$ pressure and seam depth. 
Finally, the observed $\mathrm{CO}_{2}$ storage capacity of the tested coal under various conditions revealed that $\mathrm{CO}_{2}$ storage capacity in a coal seam is greater at lower depths and higher $\mathrm{CO}_{2}$ injection pressures. However, the reduction of $\mathrm{CO}_{2}$ storage capacity with depth was not significant, which is important for field $\mathrm{CO}_{2}$ sequestration projects, which normally use deep seams to store $\mathrm{CO}_{2}$.

\section{Acknowledgements}

513 The authors wish to express their appreciation for the funding provided by the Australian Research 514 Council (DE130100124).

\section{References}

516 Day S, Fry R, Sakurovs R (2008) Swelling of Australian coals in supercritical $\mathrm{CO}_{2}$. International Journal of Coal Geology 74:41-52

De Silva PNK (2013) A study of $\mathrm{CO}_{2}$ storage capacity in sedimentary rocks. PhD dissertation, Monash University, Melbourne, Australia.

Hol S, Spiers CJ (2012) Competition between adsorption-induced swelling and elastic compression of coal at $\mathrm{CO}_{2}$ pressures up to $100 \mathrm{MPa}$. Journal of the Mechanics and Physics of Solids 60:1862-1882

Jasinge D (2010) An investigation of the effect of carbon dioxide sequestration on the behaviour of brown coal. PhD dissertation, Monash University, Melbourne, Australia.

Xie J, Gao M, Yu B, Zhang R, Jin W (2015) Coal permeability model on the effect of gas extraction within effective influence zone. Geomechanics and Geophysics for Geo-Energy and GeoResources 1:15-27

Larsen JW, Flowers RA, Hall PJ, Carlson G (1997) Structural rearrangement of strained coals. Energ Fuel 11:998-1002 
Liu Q, Cheng Y, Ren T, Jing H, Tu Q, Dong J (2016) Experimental observations of matrix swelling area propagation on permeability evolution using natural and reconstituted samples. Journal of Natural Gas Science and Engineering 34:680-688

Masoudian MS, Airey DW, El-Zein A, (2014) Experimental investigations on the effect of $\mathrm{CO}_{2}$ on mechanics of coal. International Journal of Coal Geology 128:12-23

McLinden M, Klein S, Lemmon E, Peskin A (1998) REFPROP, Thermodynamic and transport properties of refrigerants and refrigerant mixtures. NIST Standard Reference Database 23, Gaithersburg, MD.

Merkel A, Gensterblum Y, Krooss BM, Amann A (2015) Competitive sorption of $\mathrm{CH}_{4}, \mathrm{CO}_{2}$ and $\mathrm{H}_{2} \mathrm{O}$ on natural coals of different rank. International Journal of Coal Geology 150-151:181192

Pan Z, Connell LD (2007) A theoretical model for gas adsorption-induced coal swelling. International Journal of Coal Geology 69:243-252

Pan Z, Connell LD, Camilleri M (2010) Laboratory characterisation of coal reservoir permeability for primary and enhanced coalbed methane recovery. International Journal of Coal Geology 82:252-261

Perera MSA, Ranjith PG, Airey DW, Choi SK (2011) Sub- and super-critical carbon dioxide flow behavior in naturally fractured black coal: An experimental study. Fuel 90:3390-3397

Ranathunga AS, Perera MSA, Ranjith PG, Ju Y, Vishal V, De Silva PNK (2015) A macro-scale experimental study of sub-and super-critical $\mathrm{CO}_{2}$ flow behaviour in Victorian brown coal. Fuel 158:864-873

Ranathunga AS, Perera MSA, Ranjith PG (2016) Super-critical carbon dioxide flow behaviour in low rank coal: A meso-scale experimental study. Journal of $\mathrm{CO}_{2}$ Utilization (under review)

Sun Y, Li Q, Yang D, Liu X (2016) Laboratory core flooding experimental systems for $\mathrm{CO}_{2}$ geosequestration: An updated review over the past decade. Journal of Rock Mechanics and Geotechnical Engineering 8:113-126 
556 Siriwardane H, Haljasmaa I, McLendon R, Irdi G, Soong Y, Bromhal G (2009) Influence of carbon dioxide on coal permeability determined by pressure transient methods. International

Vishal V, Singh TN (2015) A Laboratory Investigation of Permeability of Coal to Supercritical Journal of Coal Geology 77:109-118.

Verma AK, Sirvaiya A (2016) Comparative analysis of intelligent models for prediction of Langmuir constants for $\mathrm{CO}_{2}$ adsorption of Gondwana coals in India. Geomechanics and Geophysics for Geo-Energy and Geo-Resources 2:97-109

564 Wang S, Elsworth D, Liu J (2013) Permeability evolution during progressive deformation of intact 565 coal and implications for instability in underground coal seams. International Journal of Rock $566 \quad$ Mechanics and Mining Sciences 58:34-45

567 Wang Y, Liu S, Elsworth D (2015) Laboratory investigations of gas flow behaviors in tight 568 anthracite and evaluation of different pulse-decay methods on permeability estimation. 569 International Journal of Coal Geology 149:118-128

570 White CM, Smith DH, Jones KL, Goodman AL, Jikich SA, LaCount RB, DuBose SB, Ozdemir E, 571 Morsi BI, Schroeder KT (2005) Sequestration of Carbon Dioxide in Coal with Enhanced 572 Coalbed Methane Recovery: A Review. Energy and Fuels 19:659-724 


\section{University Library}

\section{- MINERVA \\ A gateway to Melbourne's research publications}

Minerva Access is the Institutional Repository of The University of Melbourne

Author/s:

Ranathunga, AS;Perera, MSA;Ranjith, PG;De Silva, GPD

Title:

A macro-scale view of the influence of effective stress on carbon dioxide flow behaviour in coal: an experimental study

Date:

2017-03-01

Citation:

Ranathunga, A. S., Perera, M. S. A., Ranjith, P. G. \& De Silva, G. P. D. (2017). A macroscale view of the influence of effective stress on carbon dioxide flow behaviour in coal: an experimental study. GEOMECHANICS AND GEOPHYSICS FOR GEO-ENERGY AND GEORESOURCES, 3 (1), pp.13-28. https://doi.org/10.1007/s40948-016-0042-2.

Persistent Link:

http://hdl.handle.net/11343/283309 